EXTENDED REPORT

\title{
Circadian melatonin and cortisol levels in rheumatoid arthritis patients in winter time: a north and south Europe comparison
}

\author{
M Cutolo, G J M Maestroni, K Ołsa, O Aakre, B Villaggio, S Capellino, P Montagna, L Fazzuoli, \\ T Veldi, T Peets, E Hertens, A Sulli
}

See end of article for authors' affiliations ......................

Correspondence to: Professor M Cutolo, Division of Rheumatology, Department of Internal Medicine, University of Genova, Viale Benedetto $\mathrm{XV}, 6,16136$ Genova, Italy; mcutolo@unige.it

Accepted 17 July 2004

\begin{abstract}
Background: Altered functioning of the hypothalamic-pituitary-adrenal axis and altered melatonin production might modulate the circadian symptoms in patients with rheumatoid arthritis.

Objective: To investigate the influence of different winter photoperiods on the circadian rhythms of serum melatonin, cortisol, tumour necrosis factor $\alpha$ (TNF $\alpha$ ), and interleukin 6 (IL6) in patients with rheumatoid arthritis from a north Europe country (Estonia) and a south Europe country (ltaly).

Methods: The patients from Estonia $(n=19)$ and Italy $(n=7)$ had similar disease severity and duration and were compared with healthy age and sex matched controls in the two countries. Blood samples were collected during the period January to February at 8 pm, 10 pm, midnight, $2 \mathrm{am}, 4 \mathrm{am}, 6 \mathrm{am}, 8 \mathrm{am}$, and $3 \mathrm{pm}$. Melatonin was measured by radioimmunoassay using ${ }^{125}$-melatonin. Serum cortisol, TNF $\alpha$, and IL6 cytokines were assayed by standard methods.

Results: Higher circadian melatonin concentrations from $10 \mathrm{pm}$ and an earlier peak were observed in Estonian patients than in their age and sex matched controls $(p<0.01)$. Starting from midnight, melatonin concentrations were significantly higher in the Estonian patients than in the Italian patients. No significant differences were observed for serum cortisol. Serum TNF $\alpha$ was higher $(p<0.05)$ in Estonian patients than in their controls and was correlated with the melatonin levels.

Conclusions: In a north European country (Estonia), the circadian rhythm of serum concentrations of melatonin and $\mathrm{TNF} \alpha$ in patients with rheumatoid arthritis were significantly higher than in matched controls or in rheumatoid patients from a south Europe country (Italy).
\end{abstract}

A ltered functioning of the hypothalamic-pituitary-adrenal axis seems to be an important factor in the circadian nature of the symptoms of rheumatoid arthritis, ${ }^{1}$ with joint stiffness and pain being more prominent in the early morning. Human proinflammatory cytokine production also shows diurnal rhythmicity, with peak levels during the night and early morning, at a time when plasma cortisol is lowest. ${ }^{2}$ An inappropriately low secretion of cortisol is a typical feature of the inflammatory disease in patients with rheumatoid arthritis.

Cortisol may not be the only hormone affecting the circadian rhythms of cytokines and inflammation, however. Another strong candidate is the pineal indoleamine melatonin, the synthesis and secretion of which is regulated by the photoperiod, with peak levels during the night and in the hours of darkness, while sunlight suppresses its secretion. ${ }^{34}$ The circadian nocturnal release of melatonin has a profound influence on the internal environment of the organism, producing various different physiological effects. ${ }^{5}$ In peripheral blood mononuclear cells, melatonin has been reported to stimulate the production of interleukin 6 (IL6), T helper cell type 1 (Th1) related cytokines such as interleukin 2 (IL2) and interferon $\gamma$, but not interleukin $4 .{ }^{6}$ Physiologically, the nocturnal melatonin peak has been associated with a high interferon $\gamma$ (IFN $\gamma$ )/interleukin 10 ratio-that is, the melatonin rhythm is positively correlated with the rhythmicity of the Thl to Th2 ratio. ${ }^{78}$

Of relevance to rheumatoid arthritis, melatonin can promote collagen induced arthritis in mice and stimulate primary cultures of synovial macrophages from patients with rheumatoid arthritis to produce interleukin 12 as well as nitric oxide. ${ }^{9}{ }^{10}$
Recent studies indicate that melatonin production in patients with rheumatoid arthritis seems to be greater than in healthy controls at the beginning of the night and in the early morning. ${ }^{11}$ Interestingly, the melatonin increase in the early morning was found to correlate with the typical peak of joint stiffness and pain.

Other studies and reviews have examined the epidemiological evidence that suggests that ultraviolet radiation (UVR) may play a protective role in rheumatoid arthritis, and a gradient of increasing incidence of rheumatoid arthritis with latitude has also been reported. ${ }^{12}$ We therefore evaluated the circadian rhythms of serum melatonin, cortisol, $\mathrm{TNF} \alpha$, and IL6 in patients with rheumatoid arthritis from a north European country (Estonia) and compared the melatonin and cortisol levels with those of rheumatoid patients from a south European country (Italy), to detect a possible influence of different winter photoperiods.

\section{METHODS}

The Estonian patients were recruited at the Tallinn Central Hospital during the winter time (mean sunrise 9.19 am to mean sunset $3.29 \mathrm{pm}$ ). Nocturnal serum levels of melatonin were evaluated in 19 patients with rheumatoid arthritis (mean (SD) age, 51 (14) years; four male, 15 female; rheumatoid arthritis functional class II and III, DAS 4.2) and in 10 healthy control subjects (age 50 (15) years; six female, four male). Seven Estonian rheumatoid patients over 60 years old (mean age, 66 (5) years; five female, two male; DAS 4.2) and seven healthy controls were compared with

Abbreviations: DAS, disease activity score; IL6, interleukin 6; TNF $\alpha$, tumour necrosis factor $\alpha$; UVR, ultraviolet radiation 
seven age and sex matched Italian rheumatoid patients (mean age, 66 (7) years; DAS 4.5) and seven healthy controls recruited at the rheumatological division of the Genova University (mean sunrise 8 am to mean sunset $5 \mathrm{pm}$ ), to compare the hormonal circadian rhythms in relation to different durations of daily darkness. The mean disease duration was 4 (3) years.

The diagnosis of rheumatoid arthritis fulfilled the American College Rheumatology (ACR) criteria, and informed consent to participate in the study was obtained from all the patients. Patients were treated with nonsteroidal anti-inflammatory drugs (voltaren, naproxen, or ketoprofen) and antacids. None was taking corticosteroids or disease modifying antirheumatic drugs during the last two months before entry to the study, nor were any patients on $\mathrm{TNF} \alpha$ blockers or other anticytokine treatment.

Blood samples were obtained at $8 \mathrm{pm}, 10 \mathrm{pm}$, midnight, $2 \mathrm{am}, 4 \mathrm{am}, 6 \mathrm{am}, 8 \mathrm{am}$, and $3 \mathrm{pm}$ and were drawn in dim red light. The patients and the healthy controls were asked to stay in their dark room all night.

Melatonin was measured by radioimmunoassay (RIA), using ${ }^{125}$ I-melatonin (DDV Diagnostica, Marburg, Germany). The sensitivity of the method was of $2 \mathrm{pg} / \mathrm{ml}$ and the interassay variability less than $15 \%$. The antimelatonin antibody used had a cross reactivity of $>0.1 \%$ with melatonin related metabolites or precursors.

Serum concentrations of cortisol were assayed by the chemiluminescent method (DPC, Los Angeles, California, USA) with a sensitivity of $0.2 \mu \mathrm{g} / \mathrm{dl}$ and intra-assay and interassay coefficient of variation $(\mathrm{CV})$ of $6.5 \%$ and $7.8 \%$, respectively. The cortisol results are expressed as $\mathrm{ng} / \mathrm{ml}$.

An enzyme linked immunosorbent assay (ELISA) was used to measure serum levels of IL6 and TNF $\alpha$ (Diaclon, Becancon,
France). Blood samples were centrifuged immediately after collection. Serum tubes were frozen at $-70^{\circ} \mathrm{C}$ and all samples were tested at the same time. Each kit specifically measures both natural and recombinant human TNF $\alpha$ and IL6, showing no detectable cross reaction with other cytokines. Sensitivity was $10 \mathrm{pg} / \mathrm{ml}$ for TNF $\alpha$ and $2 \mathrm{pg} / \mathrm{ml}$ for IL6. For $\mathrm{TNF} \alpha$, intra-assay and interassay CV values were $1.97 \%$ and $3.85 \%$, respectively; for IL6 the values were $2.34 \%$ and $3.86 \%$. Results were expressed in $\mathrm{pg} / \mathrm{ml}$. All samples were tested three times and values are given as mean (SD).

\section{Statistical analysis}

Statistical analysis was carried out using analysis of variance (ANOVA) and confirmed by the non-para-metric Wilcoxon signed rank test to compare continuous variables, and by the Mann-Whitney U test to compare continuous variables with nominal variables. Regression and Spearman rank tests were used to evaluate any possible correlations between continuous variables. A probability (p) value of less than 0.05 was considered statistically significant.

\section{RESULTS}

\section{Estonian rheumatoid patients $v$ their matched controls} Hormones

Circadian concentrations of melatonin in Estonian rheumatoid patients and controls are given in fig l, top left. There was a higher melatonin concentration at $10 \mathrm{pm}$ in the rheumatoid patients than in their age and sex matched controls, at $26.8(76.8) v 3.8(5.4) \mathrm{pg} / \mathrm{ml}(\mathrm{p}<0.01)$. A higher melatonin concentration was present in the rheumatoid patients throughout the night and early morning, with significant differences at $4 \mathrm{am}$ and $6 \mathrm{am}$ (38.1 (56.2) and 30.0 (51.0) pg/ml, respectively, $v 16.2$ (15.5) and 6.7 (8.6) pg/ml in
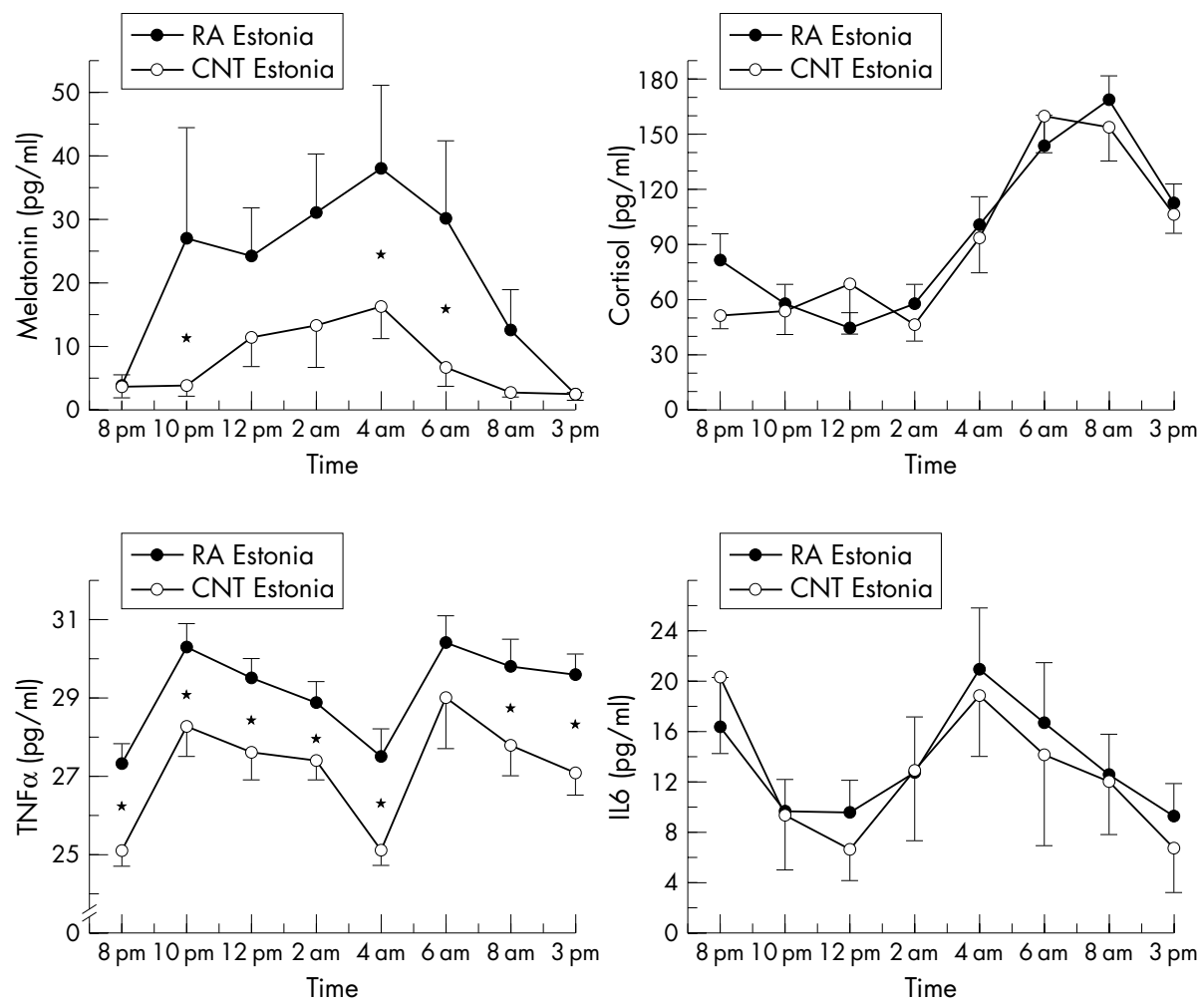

Figure 1 Circadian rhythms of melatonin, cortisol, tumour necrosis factor $\alpha$ (TNF $\alpha$ ), and interleukin 6 (IL6) in Estonian patients with rheumatoid arthritis (mean (SD) age, 51 (14) years, $n=19$ ) versus sex and age matched healthy control subjects (mean age, $50(15)$ years, $n=10)$. Melatonin levels were higher in rheumatoid patients than controls at $10 \mathrm{pm}\left({ }^{*} \mathrm{p}<0.01\right)$ and at 4 am and $6 \mathrm{am}\left({ }^{*} \mathrm{p}<0.05\right)$. TNF $\alpha$ levels were higher in rheumatoid patients than controls at $8 \mathrm{pm}, 10 \mathrm{pm}$, and midnight, and at $2 \mathrm{am}, 4 \mathrm{am}, 8 \mathrm{am}$, and $3 \mathrm{pm}\left({ }^{*} \mathrm{p}<0.05\right)$. Values are means, error bars $=S E M$. RA, rheumatoid arthritis. 

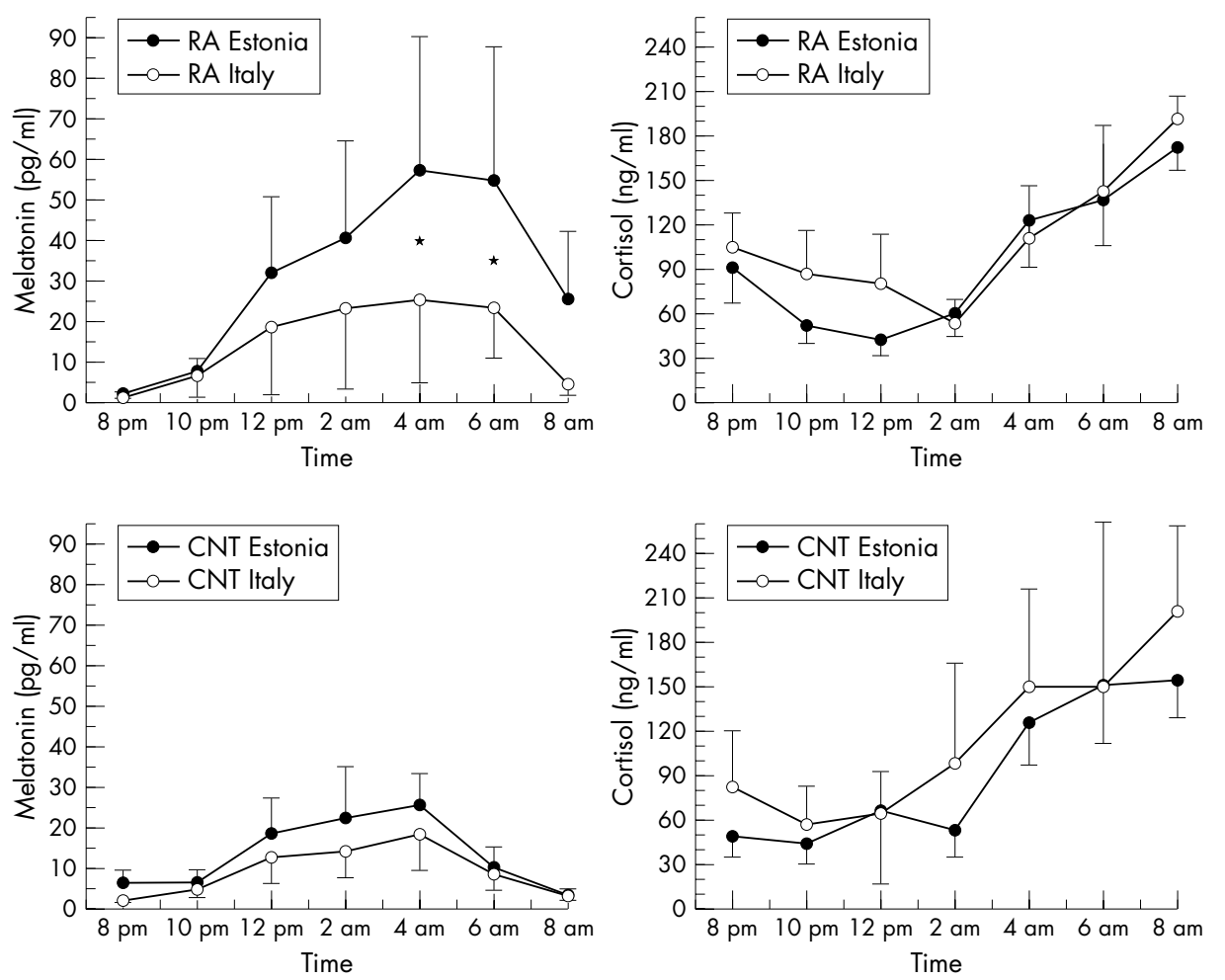

Figure 2 Circadian rhythms of melatonin and cortisol in Estonian patients with rheumatoid arthritis (mean (SD) age, 66 (5) years; $n=7$ ) and in sex and age matched Estonian controls $(n=7)$ compared with Italian rheumatoid patients (mean age, $66(7)$ years; $n=7)$ and ltalian controls $(n=7)$. Melatonin was higher in Estonian patients than in Italian patients at 4 am and 6 am ( $\left.{ }^{*} p<0.05\right)$. Values are means, error bars $=S E M$. CNT, control; RA, rheumatoid arthritis.

the controls $(p<0.05))$. Melatonin values in the rheumatoid patients at 8 am were very similar to the values in the controls at their circadian peak (4 am), at $12.6(27.4) v 16.2$ (15.5) $\mathrm{pg} / \mathrm{ml}$, respectively. The values at $8 \mathrm{am}$ in the control group were even lower than at $8 \mathrm{pm}$, at 2.7 (1.9) $v 3.8$ (5.4) $\mathrm{pg} / \mathrm{ml}$, respectively. Serum melatonin values in both the rheumatoid group and the controls were highly variable during the study, in spite of reasonable age matching. This is consistent with a previous report showing that melatonin levels in humans have high interindividual variability, even in age and sex matched populations. ${ }^{3}$

No significant difference was observed for serum cortisol between the Estonian rheumatoid patients and the controls (fig 1, top right). The cortisol peak was observed two hours earlier in the controls $(6 \mathrm{am})$ than in the rheumatoid patients (8 am), the values being $160.0(64.2) v 168.4(57.0) \mathrm{pg} / \mathrm{ml}$, respectively.

\section{Cytokines}

As expected, TNF $\alpha$ serum levels were significantly higher in the Estonian rheumatoid patients than in the controls (excluding the 6 am value) ( $p<0.05$; fig 1 , bottom left). A double peak was observed in both the rheumatoid group and the control group-at $10 \mathrm{pm}$ and $6 \mathrm{am}$-the values being $30.3(2.8) \vee 28.3(2.6) \mathrm{pg} / \mathrm{ml}$ and 30.4 (2.7) v 30.8 (4.1) pg/ml, respectively.

No significant differences were observed in IL6 values between Estonian rheumatoid patients and the controls (fig l, bottom right).

A correlation analysis was done between hormones and cytokines in the Estonian rheumatoid patients. A significant correlation was found between melatonin and TNF $\alpha$ at $8 \mathrm{pm}$ $(\mathrm{p}<0.01), 2$ am $(\mathrm{p}<0.02), 4$ am $(\mathrm{p}<0.003), 8$ am $(\mathrm{p}<0.007)$.
No significant correlations were found between melatonin and IL6 or between cortisol and either TNF $\alpha$ or IL6.

\section{Estonian $v$ Italian rheumatoid patients}

Melatonin serum concentrations were significantly higher in the Estonian than in the Italian rheumatoid patients by midnight, at 32.2 (49.0) $v 18.9$ (37.4) pg/ml, respectively $(\mathrm{p}<0.05)$, and were still higher at the later time points (fig 2, top left). The difference between the Estonian and the Italian melatonin concentrations was still significant at the time of the circadian peak (4 am), at $57.4(86.8) v 25.5$ (45.8) pg/ml $(\mathrm{p}<0.05)$, and the values remained higher at $8 \mathrm{am}(25.8$ $(43.5) v 4.7(5.3) \mathrm{pg} / \mathrm{ml}(\mathrm{p}<0.05))$. The melatonin concentrations at $8 \mathrm{am}$ in the Estonian rheumatoid patients were similar to the highest night time values observed in the Italian patients (4 am; 25.5 (45.8) pg/ml).

In contrast, at $8 \mathrm{pm}, 10 \mathrm{pm}$, and midnight, lower cortisol concentrations (at the limit of significance) were observed in the Estonian rheumatoid patients compared with the Italian patients, at $92.0(64.6), 53.0$ (33.3), and $47.4(27.2) \mathrm{pg} / \mathrm{ml}, v$ 105.4 (51.9), $87.2(67.2)$, and 80.9 (74.0) pg/ml, respectively (fig 2, top right).

\section{DISCUSSION}

This study shows for the first time that in rheumatoid patients from a north Europe country (Estonia) the circadian rise in serum melatonin is significantly greater than in matched patients from a south Europe country (Italy). In addition, we confirmed that melatonin levels are increased in rheumatoid patients compared with sex and age matched healthy controls.

Melatonin has been reported to stimulate the production of IL6 and Thl related proinflammatory cytokines such as IL12, 
IL1, IL2, and interferon $\gamma$, which are involved in the pathophysiology of rheumatoid arthritis..$^{13}$

The synthesis and secretion of melatonin is regulated by the photoperiod, with peak levels during the night and darkness hours, while sunlight suppresses its secretion. ${ }^{34}$ The clinical symptoms of rheumatoid arthritis also show a circadian variation, with joint stiffness and pain being more prominent in the early morning. ${ }^{14}$ At that time, human proinflammatory cytokine production is at peak levels. ${ }^{2}$

Melatonin is synthesised in human bone marrow cells. ${ }^{15}$ However, it has been found to be present at a rather high concentration in synovial fluid from rheumatoid patients, and recently it has been reported that synovial macrophages from rheumatoid patients have specific binding sites for melatonin. ${ }^{16}{ }^{17}$

The apparent immune suppressive effect of ultraviolet radiation suggests that this environmental exposure may modulate the development of immune related disorders, including rheumatoid arthritis. ${ }^{18}$ Thus the inhibitory effect of the UVR associated visible light wavelengths on melatonin synthesis might play a role in rheumatoid pathophysiology. On the other hand, there are data showing that in the northern hemisphere the onset of rheumatoid arthritis from October to March is twice as frequent as in the other months. ${ }^{19}$ Recent studies have analysed the possible relation between relapse onset in rheumatoid arthritis and the solar light duration in summer time and shown a low correlation..$^{20}$ However, there are now epidemiological studies to suggest that UVR may play a protective role in rheumatoid arthritis, and a gradient of increasing incidence of rheumatoid arthritis with latitude has been reported. ${ }^{12}$ The prevalence of rheumatoid arthritis is in fact much higher in north Europe than in the Mediterranean countries, with rates of $1.96 \%$ in Finland, $1.1 \%$ in England, $0.9 \%$ in Sweden, Denmark, and Netherlands $v 0.2 \%$ in Greece and $0.3 \%$ in Italy and Israel. ${ }^{21} 22$

In adult primates, only visible light $(400-700 \mathrm{~nm})$ is received by the retina. This photic energy is then transduced and delivered to the visual cortex and, by an alternative pathway, to the suprachiasmatic nucleus, the hypothalamic region which controls circadian rhythms. Visible light exposure modulates the pituitary and pineal glands, leading to neuroendocrine changes. Melatonin, noradrenaline, and acetylcholine decrease with light activation, whereas cortisol, serotonin, GABA, and dopamine levels increase. ${ }^{23}$ In normal subjects, melatonin peaks at approximately $3 \mathrm{am}$, whereas cortisol peaks at approximately $9 \mathrm{am}^{24}$

An inappropriate low secretion of cortisol is a typical feature of the inflammatory disease in patients with rheumatoid arthritis. ${ }^{25} 26$ On the other hand, in our study the nocturnal rhythm of melatonin in rheumatoid patients showed an earlier peak level in the evening and a longer duration of increased levels compared with south European patients (and the controls). An imbalance between the antiinflammatory effects exerted by cortisol and the proinflammatory effects exerted by melatonin during the night seems probable in all rheumatoid patients, and particularly in those living in the north. ${ }^{27-29}$

The association of high melatonin with low cortisol in rheumatoid arthritis could depend on a variety of factors. One of these might be an abnormal response to bright light in patients with rheumatoid arthritis. It has been shown that the transition from dim light to bright light in the morning results in an immediate surge of cortisol in healthy individuals. ${ }^{30}$ This hypothesis would fit with the observed reduction in melatonin inhibition (higher melatonin values) at the end of the hours of darkness. A decreased light sensitivity in rheumatoid patients might result in higher melatonin concentrations, which in turn shorten or decrease the cortisol peak. Indeed, it has been reported that exogenous melatonin shortens the cortisol rhythm in blind subjects. ${ }^{31}$

Thus rheumatoid arthritis may develop preferentially in individuals with a somewhat reduced neuroendocrine response to the light phase of the photoperiod. On this basis, the northern type photoperiod might favour the development of the disease by its particular lack of sunlight during the winter months.

Serum $T N F \alpha$, the most representative expression of proinflammatory cytokine production in rheumatoid arthritis, consistently showed a circadian rhythmicity with peak levels during the night, at the time when plasma cortisol is low and melatonin is higher. The presence of two TNF $\alpha$ peaks, which were correlated with the melatonin peaks, is of interest. However, the TNF $\alpha$ gap observed during the night between the two peaks might reflect the influence of the early rise of cortisol, which starts to downregulate TNF $\alpha$ production. It is in any case insufficient to control the inflammatory reaction of rheumatoid arthritis.

The administration of physiological doses of hydrocortisone has been found to suppress $\mathrm{TNF} \alpha$ production compared with ILl and IL6. ${ }^{32}$ Thus the prolonged seasonal and daily darkness observed in winter time in Estonia (almost 19 hours a day in Tallinn) versus the much shorter period in Italy (almost 15 hours a day in Genova) could be implicated in the significantly higher and more prolonged serum melatonin concentrations observed in our study. The annual average UVR levels decrease with increasing latitude, and the UVR difference is much more evident in midwinter than in midsummer. ${ }^{33}$ In addition, the photoperiod (day length) is the principal proximate factor regulating the timing of seasonal adaptations in many species, and melatonin seems to mediate seasonal changes in immune function. $^{34}$

Other UVR related factors may be involved; for example, some studies indicate that any beneficial effect of URV on autoimmune diseases, including rheumatoid arthritis, could be mediated through photosynthesised vitamin D. ${ }^{33}$ However, the differences in disease incidence among darkly and lightly pigmented people, particularly with respect to multiple sclerosis, do not support this hypothesis. ${ }^{33}$ In addition, the lower than expected concentrations of cortisol already reported in rheumatoid patients may be related to the hyporesponsiveness of the hypothalamic-pituitary-adrenal axis that is described in chronic inflammation, and might further be implicated in the unopposed (by cortisol) increase in synthesis of melatonin during the night.

Finally, the higher prevalence of autoimmune diseases such as rheumatoid arthritis that is observed in north Europe when compared with the Mediterranean countries might also be related to a strengthening of the immune enhancing effect exerted during the night by melatonin and by a somewhat reduced neuroendocrine response to the light phase of the photoperiod. A larger sample of rheumatoid patients needs to be studied and further data are required for a better understanding of these relations.

\section{ACKNOWLEDGEMENTS}

The research was partially supported by the Italy-Ministry Cooperation Project from the Italian Ministry for Foreign Affairs.

\section{Authors' affiliations}

M Cutolo, B Villaggio, S Capellino, P Montagna, A Sulli, Division of Rheumatology, Department of Internal Medicine, University of Genova, Genova, Italy

G J M Maestroni, E Hertens, Cantonal Institute of Pathology, Locarno, Switzerland

K Otsa, O Aakre, T Veldi, T Peets, Division of Rheumatology, Tallinn

Central Hospital, Tallinn, Estonia 
L Fazzuoli, Division of Endocrinology, Department of Endocrinology, University of Genova

\section{REFERENCES}

1 Straub R, Cutolo M. Impact of the hypothalamic-pituitary-adrenal/gonadal axes and the peripheral nervous system in rheumatoid arthritis: a systemic pathogenic view point. Arthritis Rheum 2001;44:493-507.

2 Petrovsky N, Harrison L. The chronobiology of human cytokine production. Int Rev Immunol 1998; 16:635-49.

3 Yu HS, Tsin ATC, Reiter RJ. MLT: history, biosynthesis, and assay methodology. In: Yu HS, Reiter RJ, eds. MLT. Biosynthesis, physiological effects, and clinical applications. Boca Raton: CRC Press, 1993:1-17.

4 Lemire JM. Immunomodulatory role of 1,25-dihydroxyvitamin D3. J Cell Biochem 1992;49:26-31.

5 Maestroni GJM. The immunotherapeutic potential of MLT. Exp Opin Invet Drugs $2001 ; 10: 467-76$

6 Garcia-Maurino S, Gonzales-Haba MG, Calvo JR, Rafii-El-Idrissi M, Sanchez-Margalet V, Goberna R, et al. MLT enhances IL-2, IL-6, and IFNgamma production by human circulating CD4+ cells: a possible nuclear receptor-mediated mechanism involving $T$ helper type 1 lymphocytes and monocytes. J Immunol 1997;159:574-81.

7 Petrovsky N, Harrison L. Diurnal rhythmicity of human cytokine production: a dynamic disequilibrium in T helper cell type 1/T helper cell type 2 balance. J Immunol 1996;158:5163-8.

8 Maestroni GJM. T-helper 2 lymphocytes as a peripheral target of MLT. J Pineal Res 1995; 18:84-9.

9 Hansson I, Holmdahl R, Mattsson R. The pineal hormone MLT exaggerates development of collagen-induced arthritis in mice. J Neuroimmunol 1992;39:23-31.

10 Cutolo M, Villaggio B, Candido F, Valenti S, Giusti M, Felli L, et al. MLT influences interleukin-12 and nitric oxide production by primary cultures of rheumatoid synovial macrophages and THP-1 cells. Ann NY Acad Sci 1999;876:246-54.

11 Sulli A, Maestroni GJM, Villaggio B, Hertens E, Craviotto C, Pizzorni C, et al. MLT serum levels in rheumatoid arthritis. Ann NY Acad Sci 2002;966:276-83

12 Cantorna MT. Vitamin D and autoimmunity: is vitamin D status an environmental factor affecting autoimmune disease prevalence? Proc Soc Exp Biol Med 2000;223:230-3.

13 Firestein GS. Evolving concepts of rheumatoid arthritis. Nature 2003;423:356-61

14 Cutolo M, Seriolo B, Craviotto C, Pizzorni C, Sulli A. Circadian rhythms in RA. Ann Rheum Dis 2003:62:593-6.

15 Conti A, Conconi S, Hertens E, Skwarlo-Sonta K, Markowska M, Maestroni G. Evidence for MLT synthesis in mouse and human bone marrow cells. J Pineal Res 2000;28:193-202.

16 Maestroni G, Sulli A, Pizzorni C, Villaggio B, Cutolo M. MLT in rheumatoid arthritis: a disease promoting and modulating hormone? Clin Exp Rheumatol 2002;20:872-3.

17 Maestroni GJM, Sulli A, Pizzorni C, Villaggio B, Cutolo M. MLT in rheumatoid arthritis: synovial macrophages show MLT receptors. Ann NY Acad Sci 2002;966:271-5
18 Staples JA, Ponsonby AL, Lim LL, McMichael AJ. Ecologic analysis of some immune-related disorders, including type 1 diabetes, in Australia: latitude, regional ultraviolet radiation, and disease prevalence. Environ Health Perspect 2003;111:518-23.

19 Jacoby RK, Jayson MI, Cosh JA. Onset, early stages, and prognosis of rheumatoid arthritis: a clinical study of 100 patients with 11-year follow-up. BMJ, 1973;ii, 96-100.

20 Rozin A, Balbir-Gurman A, Schapira D. Seasonal distribution of relapse onset in rheumatoid arthritis and spondyloarthropathy: the possible effect of solar factor. Clin Exp Rheumatol 2003;21:161-70.

21 Abdel-Nasser AM, Rasker JJ, Valkenburg HA. Epidemiological and clinical aspects relating to the variability of rheumatoid arthritis. Semin Arthritis Rheum 1997;27:123-40.

22 Spector TD. Rheumatoid arthritis. Rheum Dis Clin North Am 1990;16:513-37.

23 Roberts JE. Light and immunomodulation. Ann NY Acad Sci 2000;917:435-45

24 Miyatake A, Morimoto Y, Uishi T. Circadian rhythm of serum testosterone and its relation to sleep: comparison with the variation in serum luteinizing hormone, prolactin, and cortisol in normal men. J Clin Endocrinol Metab 1980;51:1365-71.

25 Straub RH, Paimela L, Peltomaa R, Schölmerich J, Leirisalo-Repo M Inadequately low serum levels of steroid hormones in relation to IL-6 and TNF in untreated patients with early rheumatoid arthritis and reactive arthritis. Arthritis Rheum 2002;46:654-62.

26 Dekkers JK, Greenen R, Godaert GLR, van Doornen UP, Bijlsma LWJ. Diurnal rhythm of salivary cortisol levels in patients with recent-onset rheumatoid arthritis. Arthritis Rheum 2000:43:465-7.

27 Maestroni GJ, Conti A, Pierpaoli W. Role of the pineal gland in immunity: diurnal synthesis and release of MLT modulates the antibody response and antagonizes the immunosuppressive effects of corticosterone. J Neuroimmunol 1986:13:19-26.

28 Masi AT, Chrousos GP. Hypothalamic-pituitary-adrenal-glucocorticoid axis function in rheumatoid arthritis. J Rheumatol 1996;23:577-81.

29 Maestroni GJ. The immuneneuroendocrine role of MLT. J Pineal Res 1993; 14:1-10.

30 Leproult REF, Colecchia M, Hermite-Baleriaux L, Van Cauter E. Transition from dim to bright light in the morning induces an immediate elevation of cortisol levels. J Clin Endocrinol Metab $2001 ; 86: 151-7$.

31 Hack LMSW, Lockley J, Arend T, Skene DJ. The effects of low-dose 0.5-mg MLT on the free-running circadian rhythms of blind subjects. J Biol Rhythms 2003; 18:420-9.

32 De Rijk R, Michelson D, Karp B, Petrides J, Galliven E, Deuster P, et al. Exercise and circadian rhythm-induced variations in plasma cortisol differentially regulate interleukin-1 beta (IL-1 beta), IL-6, and tumor necrosis factor-alpha (TNF alpha) production in humans: high sensitivity of TNF alpha and resistance of IL-6. J Clin Endocrinol Metab 1997;82:2182-91.

33 Ponsonby AL, McMichael A, van der Mei I. Ultraviolet radiation and autoimmune disease: insights from epidemiological research. Toxicology 2002;181-2:71-8.

34 Nelsos RJ, Drazen DL. MLT mediates seasonal changes in immune function. Ann NY Acad Sci 2000;917:404-15.

35 Cutolo M. Solar light effects on onset/relapse and circannual/circadian symptomatology in rheumatoid arthritis. Clin Exp Rheum 2003;21:148-50. 